\title{
The Misuse of Social Media and the Propagation of Incorrect Information about Diabetes
}

\author{
Edson da Silva ${ }^{1 *}$ and Marileila Marques Toledo ${ }^{2}$ \\ ${ }^{1}$ Diabetes Study Group, Department of Basic Sciences, Federal University of Jequitinhonha and Mucuri Valleys (UFVJM), Brazil \\ ${ }^{2}$ Master Degree Student in Health, Society and Environment, Federal University of Jequitinhonha and Mucuri Valleys (UFVJM), Brazil
}

*Corresponding author: Edson da Silva, Diabetes Study Group, Department of Basic Sciences, Federal University of Jequitinhonha and Mucuri Valleys (UFVJM), Brazil, Tel: +55 383532 1200; E-mail: edsondasilvaatm@ @otmail.com

Received: 08 Jan, 2019 | Accepted: 01 Feb, 2019 | Published: 05 Feb, 2019

Citation: Da Silva E, Toledo MM (2019) The Misuse of Social Media and the Propagation of Incorrect Information about Diabetes. J Diab Res Ther 5(1): dx.doi.org/10.16966/2380-5544.140

Copyright: (C) 2019 Da Silva E, et al. This is an open-access article distributed under the terms of the Creative Commons Attribution License, which permits unrestricted use, distribution, and reproduction in any medium, provided the original author and source are credited.

In recent years, there has been an important milestone with the solidification of the Internet in society, a process that has enabled the development of new technologies that have altered the health education scenario [1]. But is social media reliable, and does it propagate correct information about Diabetes Mellitus (DM) among its users?

The current literature shows that the Internet provides opportunities of communication, peer support among individuals with diabetes, their families, managers, healthcare providers, industry and the general public [2,3]. There are numerous advantages to the value of Internet use in health, including updates information on diabetes $[4,5]$. In this sense, diabetes organizations worldwide have explored the Internet as a health communication tool (e.g., International Diabetes Federation, American Diabetes Association, European Association for the Study of Diabetes and others). Further, these kinds of organizations usually use their own social media websites to increase the patient's empowerment about diabetes self-management. Although, in this editorial article we will not address such positive aspects, but some negative characteristics about the misuse of Internet in area of diabetes.

We think that all of us live in a time when we have access to all kinds of information over the Internet, including both false and true information, and more studies are required to understand this process. Adapting to new tools is not a new process in the history of communication. Uncertainties marked the initial period of cinema, radio, television, and others. One study has discussed whether digital social networks help citizens stay more informed or contribute to the dissemination of unverified information. According to the author, many users are unaware of the possibility of confirming news stories, even if they can readily do so over the Internet. Faced with this situation, the author endeavors to determine where we should look for the correct information [6].

In this context, Junior B, et al. [6] reports that false stories and rumors gained strength with the boom of social networks in Brazil, especially in the late 2000s, when Facebook created in 2004 in the United States was popularized in Brazil.

When rumors and unconfirmed news stories come out and are widely shared, we should reflection the type of information circulating on the Internet. We share, comment on, and enjoy news stories that exclude certain details or lack credible sources [6].

All this power to influence the communication of our age must be understood so that we can use the Internet and social media in our favor, as well as for the sake of education, especially health education, including DM. In this sense, we currently lack standardized tools to assess the quality of content on social media sites such as YouTube. Unlike the systematic reviews of traditional evidence, there exists a gap in the literature, with no descriptions of an evidence-based quality assessment tool for analyzing social media content [7].

New education opportunities for DM care offered through the Internet are highly important for patients and for health professionals $[8,9]$. However, in parallel with this facilitated access, the propagation of incorrect information on the Internet is growing. In this sense, systematic reviews have questioned the value of social media in the care process in several health areas [10]. For example, in a review by Williams G, et al. [11], social media interventions to promote exercise and a healthy diet were not associated with significant differences in physical activity level or weight loss.

Evidence in the literature has highlighted concerns about the regulation of content available online. A study that looked at evidence-based immunization content on YouTube showed that videos containing information that contradicted public health guidelines on the topic of interest were more likely to receive high view counts and user ratings and accounted for more than half of the YouTube content on the topic [12]. In addition, another study that examined YouTube video content about eating disorders found that one-third of the videos highly attractive to YouTube users promoted unhealthy behaviors and that these videos were more 
likely to receive a higher view count than videos that discouraged in appropriate eating habits [13].

In analyzing behavioral change through the use of social media, Maher CA, et al. [14] concluded that the effect of social media interventions on tobacco and alcohol consumption, dietary intake, and physical activity were highly variable and generally of small magnitude. Similarly, in a systematic review of 20 randomized controlled trials of online weight-management interventions, Chang $\mathrm{T}$, et al. [15] identified few studies that quantified the effect of social media on weight outcomes. These reviews may have been unable to find benefits from social media because of the heterogeneity of the included studies. For example, the impact of social media may vary according to the patient's age and the ease of use or characteristics of different technologies [10]. Similarly, variable study models, including mixed methods approaches and old-fashioned technologies, can make understanding the benefits of social media challenging.

A systematic review by Patel R, et al. [10] evaluated the clinical results of the application of contemporary social media in dealing with chronic diseases [6]. According to the authors, the use of contemporary social media technology in the treatment of chronic diseases can be categorized as support, education, modification of disease, diagnosis, or management. Based on the current literature, contemporary social media is more likely to improve care for chronic illnesses like DM when used to provide social, emotional, or experiential support. In addition, few studies suggest any harm associated with the use of contemporary social media technology in the treatment of chronic diseases. The results of the research by Patel $R$, et al. [10] show that the use of social media, particularly Facebook and blogs, provides social, emotional, or experiential support in the treatment of chronic diseases, with implications that seem to be more positive in the process involved patient care using this type of information source [9]. Thus, the enormous potential of social media to improve health and provide care is evident. Unraveling the mystery of how disease, technology, and patient factors interact to improve outcomes represents the next necessary step in this field of research.

Given the lack of knowledge about the content of its videos about DM, although YouTube is accessible worldwide, many workplaces and educational institutions restrict user access to it and other social media sites [6]. New research findings may highlight the importance of this field in leveraging YouTube's popularity as a vehicle for translating knowledge to promote evidence-based diabetes information. In addition, surveys that demonstrate the cultural value of YouTube's coupled with the potential of the social platform to share evidence-based content may be valuable in informing the future development of policies governing access to social media sites such as YouTube.

\section{Conflict of Interest}

\section{None}

\section{Source of Funding}

None

\section{References}

1. Daun F, Gambardella AMD (2016) Extensão universitária na graduação em nutrição: experiências de produção de vídeos educativos. Rev Grad USP 1: 101-105.

2. Da Silva E (2017) Internet and information technology use in diabetes education. Austin Diabetes Res 2: 1012.

3. Da Silva E, Costa JSR, Figueiredo EAB, Cunha MD, de Castro DP, et al. (2015) Diabetes Diamantina Community: a tool to promote communication and education in diabetes. Diabetol Metab Syndr 7: A175.

4. Woo BKP (2018) What Can We Learn From Diabetes-Related YouTube Videos? Can J Diabetes 42: 342

5. Alanzi T (2018) Role of Social Media in Diabetes Management in the Middle East Region: Systematic Review. J Med Internet Res 20: e58.

6. Júnior B, José D (2016) O boato na era das redes sociais digitais: uma análise do caso Guarujá. Pontifícia Universidade Católica do Rio Grande do Sul.

7. Knight E, Intzandt B, MacDougall A, Saunders TJ (2015) Information seeking in social media: a review of YouTube for sedentary behavior content. Interact J Med Res 4: e3.

8. da Silva E, Campos LF (2016) The Potential Role of Social Media and Interactive Technologies in Diabetes Education. J Dia Res Ther 2.

9. Abedin T, Ahmed S, Al Mamun M, Ahmed SW, Newaz S, et al. (2015) YouTube as a source of useful information on diabetes foot care. Diabetes Res Clin Pract 110: e1-e4.

10. Patel R, Chang T, Greysen SR, Chopra V (2015) Social media use in chronic disease: A Systematic review and novel taxonomy. Am J Med 128: $1335-1350$.

11. Williams G, Hamm MP, Shulhan J, Vandermeer B, Hartling L (2014) Social media interventions for diet and exercise behaviours: a systematic review and meta-analysis of randomised controlled trials. BMJ Open 4: e003926.

12. Grajales FJ $3^{\text {rd }}$, Sheps S, Ho K, Novak-Lauscher H, Eysenbach G (2014) Social media: a review and tutorial of applications in medicine and healthcare. J Med Internet Res 16: e13.

13. Syed-Abdul S, Fernandez-Luque L, Jian WS, Li YC, Crain S, et al. (2013) Misleading health-related information promoted through video-based social media: anorexia on YouTube. J Med Internet Res 15: e30.

14. Maher CA, Lewis LK, Ferrar K, Marshall S, De Bourdeaudhuij I, et al. (2014) Are health behavior change interventions that use online social networks effective? A systematic review. J Med Internet Res 16: e40.

15. Chang T, Chopra V, Zhang C, Woolford SJ (2013) The role of social media in online weight management: systematic review. J Med Internet Res 15: e262. 